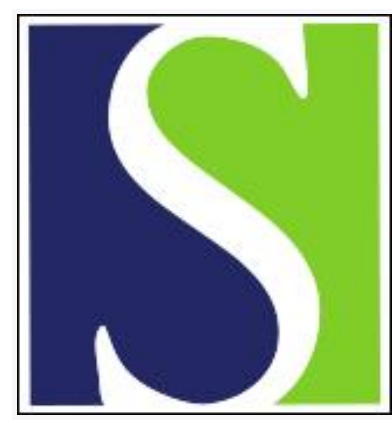

Scand J Work Environ Health 1993;19(6):432-435

https://doi.org/10.5271/sjweh.1449

Issue date: 01 Dec 1993

Re: "Urinary styrene in the biological monitoring of styrene exposure" by F Gobba, C Galassi, S Ghittori, M Imbriani, F Pugliese, A Cavaleri. Scand J Work Environ Health 1993; 19:175-82.

by Aitio $A$

This article in PubMed: www.ncbi.nlm.nih.gov/pubmed/8153598 


\section{Re: "Urinary styrene in the biological monitoring of styrene exposure" by F Gobba, C Galassi, S Ghittori, M Imbriani, F Pugliese, A Cavaleri. Scand J Work Environ Health 1993;19:175-82.}

I read with interest the paper of Dr Gobba and his co-workers on urinary styrene in the biological monitoring of styrene exposure, which recently appeared in the Journal (1). The paper presents comparative data on different approaches to the biological monitoring of styrene. The study was large and was carefully planned and executed, but it gives rise to some questions that I hope the authors can answer in the Journal.

The usefulness of a biological monitoring method is assessed with the use of all the accumulated data, and judgment is very much based on how reproducible the data are from one laboratory to another. This comparison can currently be done only from the equations of the regression lines between exposure (ie, the time-weighted concentration in the breathing zone and the concentration of the chemical or metabolite in the biological specimen). Therefore the main tools for comparison are the slope and intercept of the regression line - not the correlation coefficient. In table 5 of the article on page 180, values are given for the slopes and intercepts of the regression lines between airborne styrene concentrations and biological measures. However, no units for any measure are shown, and this lack makes the presented data difficult to interpret. For the slope, only one significant digit has been indicated for most of the parameters measured. Even if one were able to deduce from the rest of the paper the units used, the imprecision resulting from the reporting, $10-50 \%$, renders the information practically useless.

Is it correct to assume that table 5 refers to the subset of approximately 60 laminators? If so, have the authors any explanation why, in this subset (one-third of the total group), the regression line is far outside the $95 \%$ confidence range indicated in figure 1 for the total group? This possibility is especially disturbing, since the authors state: "This subgroup was fully comparable to the total group in all relevant aspects ... [p 176]." - The line of best fit for "mean concentration of styrene" in table 5 is also outside the $95 \%$ confidence limits of figure 3 .

Is it correct that, in figures $1-3$, the curved lines represent "confidence interval for the expected values," that is, individual values? They look much more like confidence intervals for the means.

In figure 3 and tables 4 and 5 , information is given on the regression line between airborne styrene concentrations over the workday and the means of two analyses of urinary styrene concentrations (noon and after shift). This kind of double urinary analyses is very seldom available in routine biological monitoring. It would be very useful if the authors could provide similar information on the regression of the time-weighted average exposure to styrene over the workday and the styrene concentration of the endof-shift urine sample. This information would also be more appropriate for use in the comparison of urinary styrene with urinary mandelic acid and phenylglyoxylic acids - for which only one urinary analysis was reported.

Dr Gobba and his co-workers find the best correlations between concentrations of styrene in air and urine and therefore conclude that this analysis is best for the biological monitoring of styrene. However, recently, another reputable group in an equally well planned and executed study came to rather opposite conclusions (2). It would be interesting if Dr Gobba and his co-workers would comment on this work, and also, if they can, compare the slopes or intercepts of the regression lines given in these two studies on the relationship between air and urinary styrene concentrations (which are very similar in several published studies on the relationship between airborne styrene and the urinary excretion of mandelic acid and phenylglyoxylic acid (3-7).

Further similar and useful comparisons can be made to the other papers on the relationship between styrene in air and in urine, such as the several earlier papers of the same groups in Pavia and Modena, cited in Dr Gobba's article.

As one of the reasons for exploring further approaches to biological monitoring, the authors give the discrepancy between the guidelines for biological action limits for urinary mandelic acid excretion, notably between the biological action limit of Deutsche Forschungsgemeinschaft $\left(2 \mathrm{~g} \cdot \mathrm{l}^{-1}\right)$ and the biological exposure index of the American Conference of Governmental Industrial Hygienists $(800 \mathrm{~g} \cdot \mathrm{g}$ creatinine $e^{-1}$. This discrepancy is, however, only apparent. The American biological exposure index is derived from the threshold limit value of $50 \mathrm{ppm}(8)$, and the German biological action limit comes from the MAK of $100 \mathrm{ppm}$, which was valid until 1987. The biological action limit was not changed when the MAK was lowered to $20 \mathrm{ppm}$ in 1987 (9). Thus the two are in fact very similar.

\section{References}

1. Gobba F, Galassi C, Ghittori S, Imbriani M, Pugliese $\mathrm{F}$, Cavalleri A. Urinary styrene in the biological mon- 
itoring of styrene exposure. Scand J Work Environ Health 1993;19:175-82.

2. Mizunuma K, Yasugi T, Kawai T, Horiguchi S, Ikeda $M$. Exposure-excretion relationship of styrene and acetone in factory workers - a comparison of a lipophilic solvent and a hydrophilic solvent. Arch Environ Contam Toxicol 1993;25(1):129-33.

3. Engström K, Härkönen H, Kalliokoski P, Rantanen J. Urinary mandelic acid concentrations after occupational exposure to styrene and its use as a biological exposure test. Scand J Work Environ Health 1976;2:21 -6.

4. Guillemin MP, Bauer D, Martin B, Marazzi A. Human exposure to styrene: IV. industrial hygiene investigations and biological monitoring in the polyester industry. Int Arch Occup Environ Health 1982;51:139-50.

5. Elia VJ, Anderson LA, MacDonald TJ, Carson A, Buncher R, Brooks SM. Determination of urinary mandelic and phenylglyoxylic acids in styrene exposed workers and a control population. Am Ind Hyg Assoc J 1980;41:922-6.

6. Bartoluzzi GB, De Rosa E Cori GP, Corona PC, Perbellini $\mathrm{L}$, Brugnone $\mathrm{F}$. Biomonitoring of occupational exposure to styrene. Appl Ind Hyg 1986;3:125-31.

7. Pekari K, Nylander-French L, Pfäffli P, Sorsa M, Aitio A. Biological monitoring of exposure to styrene assessment of different approaches. J Occup Med Toxicol. 1993;2:115-26.

8. American Conference of Governmental Industrial Hygienists (ACGIH). 1992-1993 threshold limit values for chemical substances and physical agents and biological exposure indices. Cincinnati OH: ACGIH, 1992.

9. Deutsche Forschungsgemeinschaft. Maximale Arbeitsplatzkonzentrationen und Biologische Arbeitsstofftoleranzwerte 1987: Mitteilung XXIII der Senatskommission zur Prüfung gesundheitsschädlicher Arbeitsstoffe. Weinheim: VCH Verlagsgesellschaft, 1987.

Antero Aitio, MD

Biomonitoring Laboratory

Institute of Occupational Health

Arinatie 3

FIN-00370 Helsinki

Finland

\section{Authors' reply}

The letter of Dr Aitio offers us an opportunity to introduce some aspects of our research not discussed in the article (1). The manuscript presents some of the results of a wider study on the biological monitoring of solvents. We reported the results on the relationship between the environmental levels of styrene and the values of some exposure indices currently used for biological monitoring. Currently, such a comparison is usually adopted in the assessment of the reliability of a method for biological monitoring, as stated by Dr Aitio. Nevertheless for styrene, as for other solvents, various factors, such as body burden (2), work load (3), alternative absorption routes, mainly skin (4), previous exposure (5), use of drugs or alcohol consumption (6), and differences in metabolism, can significantly interfere with the relationship between external and internal exposure and, as a consequence, also with the regression lines between the environmental levels of the solvent and the values of exposure indices. If all of these aspects are not fully controlled, the comparison of data from different studies is very difficult, and the reproducibility of the slope and of the intercept of the regression lines cannot be used to assess the usefulness of a method.

For urinary mandelic acid and phenylglyoxylic acid, the regression lines and, as a consequence, the biological equivalent exposure limits reported by different authors vary widely. (For a review see reference 7.) Nevertheless such metabolites are currently used as exposure indices, and limit values have been proposed [for instance, the biological exposure index (BEI) of the American Conference of Governmental Industrial Hygienists and the biological tolerance values for working materials (BAT) of the Deutsche Forschungsgemeinschaft] $(8,9)$.

With regard to the latter aspect, we are well aware that the difference between the BEI and BAT is due to a lack of updating of the latter value, but we reported the two limits to highlight the current discrepancy in the biological limit values proposed for styrene, the different limits being still proposed in the official documents of the authoritative institutions.

Regarding data on urinary styrene, the differences between our results and Mizunuma et al (10) can be explained in several ways, mainly as follows.

We considered samples collected after $4 \mathrm{~h}$ of exposure (from 0800 to 1200 and from 1300 to 1700), separated by a 1-h lunch break. Mizunuma et al collected samples of urine "at the 5th-6th hours of the shift [p 130]," with no details of a meal break. Differences in the results of the two groups, due to the excretion kinetics of the solvent, are therefore to be expected.

In our research, only samples of the urine produced during the whole half-shifts were considered. The workers were asked to empty their bladder just before the half-shift ( 0800 and 1300, respectively), and, if they urinated during the half shift, the samples were discarded. Mizunuma et al give no details on this aspect, but, obviously, we consider it very unlikely that they obtained urine samples of the whole period $(5-6 \mathrm{~h})$. Such an aspect is particularly relevant because the urinary concentration values for solvents eliminated unchanged (nonmetabolized portion) are "weighted" values. In fact, fluctuations in environmental levels of the solvent are rapidly reflected at the urinary level, and the bladder acts as a collection and mixing vessel for the urine formed in the kidney during the time. (For more details, see references 11 and 12.) Spot samples have, obviously, a completely different meaning from samples of the whole shift.

To avoid a loss of styrene, we collected the samples of urine in sealed vials within 2 min after voiding. Once more, no details on the matter are reported by Mizunuma et al, who observed that the correlation between environmental and urinary values was better for acetone than for styrene. Our experience 
with large groups of workers suggests, on the contrary, a similar correlation (13). The difference may be due to a loss of styrene from samples before collection in the sealed vials. In fact the urine-air partition coefficient for acetone is more than 60 times that of styrene (429 versus 6.7 , respectively) (14). Therefore, acetone is nearly 60 times more soluble in water, and a significant loss from the sample is much more unlikely, whereas styrene reaches equilibrium with the air very quickly.

Finally, we would like to consider specifically Dr Aitio's observations. First of all, the data to be presented were very numerous and, for editorial reasons, we were obliged to simplify the tables. Therefore there are no units in table 5, but the units are reported in table 4, which has to be considered together with table 5. The same applies to the few digits reported in some data in the table. However, since our paper was mainly devoted to an evaluation of urinary styrene as an index of exposure, at least two significant digits were always reported for this index. Furthermore, from a merely practical point of view, we have some doubts about the real meaning of the 4 th -5 th decimal digit of the slope. Again, for simplification, the correlation between the end-shift urinary styrene concentration and the time-weighted average exposure to styrene was not listed for the subgroup of 65 workers, but was reported for the whole group (table 2). In our study, end-of-morning and afternoon half-shift values for urinary styrene were measured to evaluate the excretion kinetics of styrene, but, for practical field activity, end-shift values of the solvent can be used instead of the "mean" urinary styrene level, without any significant loss of information.

Of course the curved lines in the figures represent the $95 \%$ confidence interval for the predicted mean values of the dependent variable, not that for the individual values; we are sorry that the text could have given space for ambiguity. The slopes of the regression lines between the external and urinary levels of styrene observed in the whole group and in the subgroup of 65 workers (which was similar to the whole group for work task, work load, external exposure, etc) are not significantly different. For medium-low exposure levels, like those usually observed currently in fiberglass reinforced-plastics plants, the differences pointed out by Dr Aitio have scant relevance from the practical point of view.

On the other hand, as clearly stated in the paper, we believe that an evaluation of the real usefulness of exposure indices, and an effective comparison of different indices, is possible only if adequate early biological effects, and exposure-effect and exposureresponse curves, are known as, for instance, has been demonstrated for lead.

A conclusive improvement in the biological monitoring of exposure to styrene (and to other solvents) will result from the evaluation of the data of research on early effects, especially those on the nervous sys- tem. Some preliminary results, such as the correlation between urinary styrene, but not metabolites, and color vision loss seem very promising and further support the usefulness of measuring the nonmetabolized portion of the solvent as an exposure index (15).

\section{References}

1. Gobba F, Galassi C, Ghittori S, Imbriani M, Pugliese F, Cavalleri A. Urinary styrene in the biological monitoring of styrene exposure. Scand J work Environ Health 1993; 19:175-82.

2. Gobba F, Galassi C, Imbriani M, Ghittori S, Cavalleri A. Kinetics of the urinary excretion of styrene during the working week and its implication in biological equivalent exposure list (BEEL) definition. In: Institute of Occupational Health. Abstracts of the International Symposium on Health Hazards of Butadiene and Styrene. Helsinki: Finnish Institute of Occupational Health, 1993:13.

3. Pezzagno G, Imbriani M, Ghittori S, Capodaglio E. Urinary concentration, environmental concentration, and respiratory uptake of some solvents: effect of work load. Am Ind Hyg Assoc J 1988;49:546-52.

4. Aitio A, Pekari H, Jarvisalo J. Skin absorption as a source of error in biological monitoring. Scand J Work Environ Health 1984;10:317-20.

5. Löf A, Lundgren E, Byfalt Nordqvist M. Kinetics of styrene in workers from a plastic industry after controlled exposure: a comparison with subjects not previously exposed. $\mathrm{Br} \mathrm{J}$ Ind Med 1986;43:537 43 .

6. Wilson HK, Robertson SM, Waldron HA, Gompertz D. Effect of alcohol on the kinetics of mandelic acid excretion in volunteers exposed to styrene vapour. $\mathrm{Br}$ J Ind Med 1983;40:75-80.

7. Guillemin MP, Berode M. Biological monitoring of styrene: a review. Am Ind Hyg Assoc J 1988;49:497505 .

8. American Conference of Governmental Industrial Hygienists (ACGIH). 1992 - 1993 threshold limit values for chemical substances and physical agents and biological exposure indices. Cincinnati OH: ACGIH, 1992.

9. Deutsche Forschungsgemeinschaft. Maximum concentrations at the workplace and biological tolerance values for working materials 1989. Weinheim: VHC Verlagsgesellschaft, 1989. (Report XXV of the Commission for the Investigation of the Health Hazards of the Chemical Compounds in the Work Area.)

10. Mizunuma K, Yasugi T, Kawai T, Horiguchi S, Ikeda $M$. Exposure-excretion relationship of styrene and acetone in factory workers: a comparison of a lipophilic solvent and a hydrophylic solvent. Arch Environ Contam Toxìcol 1993;25:129-33.

11. Pezzagno G, Ghittori S, Imbriani M, Capodaglio E. Urinary elimination of styrene in experimental and occupational exposure. Scand J Work Environ Health 1985:11:371-9.

12. Imbriani M, Ghittori S, Zadra P, Imberti R. Biological monitoring of the occupational exposure to halothane (fluothane) in operating room personnel. Am J Ind Med 1991;20:103-12.

13. Ghittori S, Imbriani M, Pezzagno G, Capodaglio E. The Urinary concentration of solvents as a biological indicator of exposure: proposal for the biological equivalent exposure limit for nine solvents. Am Ind Hyg Assoc J 1987;48:786-90.

14. Imbriani M, Ghittori S, Pezzagno G, Capodaglio E. Urine/air partition coefficients for some industrially important substances. G Ital Med Lav 1985; 7:13340. 
15. Gobba F, Galassi C, Ghittori S, Imbriani M, Candela S, Cavalleri A. Acquired dyschromatopsia among styrene exposed workers. J Occup Med 1991;33:761—5.

Fabriziomaria Gobba, MD,' Claudia Galassi, MD,' Marcello Imbriani, MD, ${ }^{2}$ Alessandro Cavalleri, $\mathrm{MD}^{3}$

1 Cattedra di Medicina del Lavoro, Universita' di Modena (Chair of Occupational Medicine, University of Modena), Via Campi 287, I-41100 Modena, Italy.

2 Dipartimento di Medicina Preventiva, Occupazionale e di Comunita', Universita' di Pavia (Department of Preventive, Occupational and Community Medicine, University of Pavia), $\mathrm{Pa}$ via, Italy.

3 Sezione di Medicina Preventiva dei Lavoratori, Università di Pavia (Section of Preventive Medicine of Workers, University of Pavia), Pavia, Italy. 